\title{
Redação de artigo científico
}

\author{
Sebastião Gusmão
}

\section{RESUMO}

Descrevem-se as orientações básicas para redação de artigo científico, tipo original, por meio da análise das diferentes partes ou seções desse tipo de trabalho. Abordam-se também as bases teóricas da redação científica e o estilo da linguagem científica.

\section{PALAVRAS-CHAVE}

Artigo científico, artigo original, redação.

\section{ABSTRACT}

This work presents a basic orientation for the writing of scientific papers type original through analysis of their component parts. The theoretical bases of scientific writing and the writing style of the scientific language are also discussed.

\section{KEYWORDS}

Scientific paper, original article, writing

O pesquisador necessita dominar a estrutura e o estilo da comunicação científica, afinal o autor de um trabalho será julgado pelo texto que apresentar.

O artigo original constitui o texto científico básico, sendo os demais (dissertação, tese, relato de caso, artigo de revisão) variações dele. Nosso objetivo é expor as normas básicas de redação do artigo original. Serão analisadas as bases teóricas da redação científica, a redação das diferentes partes ou seções desse tipo de publicação e o estilo da linguagem científica.

\section{Bases teóricas}

A lógica estabelece as regras (metodologia científica) segundo as quais o pensamento deverá proceder para chegar ao conhecimento científico. A escrita científica constitui uma continuação do fazer ciência, derivando suas normas da própria metodologia científica. A lógica da pesquisa e da comunicação determina a construção do texto científico, exigindo determinada estrutura na redação de cada etapa dele. ${ }^{9}$

Ciência são os dados e a interpretação desses dados. A redação científica é o meio para defender essa interpretação. Os dados são obtidos a partir do estudo das variáveis (tudo que pode ser estudado pelo método empírico, ou seja, por meio dos sentidos). O estudo das variáveis e a interpretação dos dados obtidos (a pesquisa) são realizados para responder a uma pergunta. Dependendo do tipo de pergunta, pode ser necessário ou não elaborar uma resposta provisória, não testada (hipótese).7,8

A pesquisa pode ser dividida em três tipos:

- descritiva (sem hipótese);

- de associação sem interferência (testa hipótese de associação);
- de associação com interferência (testa hipótese de causa e efeito).

Essa divisão determina consequências na construção e redação da pesquisa. Na pesquisa descritiva, os passos metodológicos são determinados pela pergunta, e não pela possível hipótese (desnecessária, no caso). A essência do objetivo é a descrição de uma variável, como a descrição de uma doença, uma característica (por exemplo, a altura média) dos indivíduos de determinado grupo, a estrutura de certo órgão, as relações anatômicas de determinada região do corpo humano. Do todo se descreve uma parte representativa (amostra), e dessa parte infere-se o todo.

$\mathrm{Na}$ pesquisa de associação entre duas ou mais variáveis, é necessária uma hipótese que direcione o caminho a seguir. Nesse caso, o foco não é a descrição, mas a relação entre as variáveis. Essa relação pode ser de dois tipos: sem ou com interferência. No primeiro tipo, há associação entre as variáveis que têm uma causa comum, mas não interferência de uma sobre a outra. No segundo tipo, ocorre interferência do tipo causa e efeito, por meio de determinado mecanismo, de uma sobre a outra. A pesquisa de associação implica o estudo das variáveis e o teste de associação. 
A lógica do tipo de investigação (descrição, associação ou associação com interferência) deve refletir-se ao longo de todo o texto. Assim, se o título indica estudo de associação com interferência (tipo causa e efeito), isso deve se refletir na fundamentação, no objetivo, no delineamento do trabalho e na conclusão. Todo o texto deve ser composto de partes logicamente coerentes.

O texto científico deve mostrar o que foi feito, por que foi feito, como foi feito e o que foi encontrado. Para tornar a publicação científica mais objetiva e uniforme, surgiram, ao longo dos três últimos séculos, conceitos e normas, derivados da lógica da pesquisa e da comunicação, que definem esse gênero de redação. A sequência lógica da pesquisa (o método científico) correlaciona-se precisamente com as clássicas partes da redação do texto argumentativo:

\begin{tabular}{|c|c|}
\hline REDAÇÃO & PESQUISA \\
\hline Introdução: problema & $\begin{array}{l}\text { Observação: dos fatos é } \\
\text { retirado o problema }\end{array}$ \\
\hline Desenvolvimento: solução & Experimento: solução \\
\hline Conclusão: resposta & Conclusão: resposta \\
\hline \multicolumn{2}{|c|}{$\begin{array}{l}\text { O artigo original é estruturado segundo o plano IMRED, }{ }^{1} \text { ou seja: } \\
\text { - Introdução (apresenta o problema a ser estudado) } \\
\text { - Material e Métodos (como o problema foi estudado) } \\
\text { - Resultados (qual a resposta encontrada) } \\
\text { - Discussão (o que significa essa resposta) } \\
\text { - Material e Métodos, Resultados e Discussão correspondem, na } \\
\text { redação, ao desenvolvimento para solucionar a questão colocada na } \\
\text { Introdução; a conclusão (resposta) é inserida no final da Discussão. } \\
\text { Esse plano deriva da própria lógica da pesquisa: }\end{array}$} \\
\hline PESQUISA & PLANO IMRED \\
\hline Qual é a pergunta? & Introdução \\
\hline Como foi procurada a resposta? & Material e Métodos \\
\hline Qual é a resposta? & Resultados \\
\hline O que significa a resposta? & Discussão \\
\hline
\end{tabular}

Além dessas partes, o artigo científico contém elementos complementares, sendo o texto completo constituído pelas seguintes partes: Título, Resumo, Introdução, Material e Métodos, Resultados, Discussão e Referências bibliográficas. ${ }^{2,4}$ Essa é a sequência na qual o texto é publicado, mas não necessariamente a ordem na qual é escrito ou lido.

O texto científico é do tipo argumentativo. Um argumento (dedutivo ou indutivo) é uma série de proposições (premissas) que se relacionam com outra proposição (conclusão). Não deve haver premissas desnecessárias nem faltar premissas necessárias.

O texto científico é formado por dois argumentos lógicos: um na Introdução e outro no conjunto formado por Material e Métodos, Resultados e Discussão. Na Introdução, a contextualização e a justificativa (premissas) validam o objetivo. No segundo argumento lógico, as informações derivadas de Material e Métodos, Resultados e Discussão (premissas) devem ser conectadas para sustentar a Conclusão. ${ }^{9}$
Pode-se considerar que o artigo é publicado em três versões (que aparecem de forma independente nos bancos de dados online): o Título, o Resumo e o texto propriamente dito (Introdução, Material e Métodos, Resultados e Discussão). Primeiro é lido o título e, se ele interessa ao leitor, passa-se para a leitura do resumo. Se o interesse persiste, é lido o texto propriamente dito do artigo.

Magnusson propôs a sequência backwords (de trás para frente) de redação do artigo científico: ${ }^{5}$

1. Conclusão

Inicialmente é escrita a conclusão, de forma clara e precisa. O restante do texto será estruturado em função dessa conclusão.

2. Resultados

Somente os necessários para sustentar a conclusão. Escolhe-se a melhor forma de apresentá-los (figuras, tabelas ou texto), procurando evidenciar os mais importantes para fundamentar a conclusão.

3. Material e Métodos

Somente os necessários para a obtenção dos resultados apresentados para sustentar a conclusão.

\section{Discussão}

Somente os argumentos relacionados e necessários para sustentar a conclusão.

5. Introdução

Somente o mínimo de informações necessárias para apresentar o objetivo, ou seja, o problema respondido na conclusão.

6. Título

Baseado na conclusão ou no objetivo (problema).

7. Resumo

Apresentação sintética dos pontos relevantes do texto relacionados diretamente com a conclusão.

8. Referências Bibliográficas

Somente as necessárias e essenciais para validar a Metodologia, os Resultados e a Conclusão.

Nessa sequência, inicia-se pela conclusão, que é a última parte do texto (final da Discussão) e representa a essência do artigo científico. Foca-se na Conclusão, suporta-a com Resultados, depois com os Material e Métodos, a seguir com a Discussão e, finalmente, coloca-se na Introdução a origem do processo argumentativo (o objetivo ou problema) que levou à conclusão (resposta ao problema). Isso facilita a obtenção de um texto claro e conciso, com coerência entre as partes, evitando-se desvio do ponto central (a conclusão) e informação desnecessária.

A seguir, exporemos as diferentes partes metodológicas do texto científico na sequência de escrita exposta acima (backwords). Para melhor compreensão, exemplificaremos com um artigo retirado da literatura (Gusmão SNS, Pittella JEH. Extradural haematoma and diffuse axonal injury in victims of fatal road traffic accidents. Br J Neurosurg. 1998;12:123-6). ${ }^{3}$ Antes de passar ao título seguinte, recomenda-se a leitura do resumo deste artigo no título Resumo. 


\section{Conclusão}

O texto científico é uma argumentação demonstrativa da conclusão, a resposta ao problema colocado na Introdução e que representa a essência do trabalho. Assim, ao iniciarmos uma pesquisa, devemos ter em mente de forma precisa o objetivo (o problema a ser resolvido); terminada, iniciamos a redação pela conclusão (a resposta ao problema), que será nossa guia na escrita do texto. Deve-se redigir de forma clara e precisa, no tempo presente. A conclusão será inserida no início e no final da Discussão, onde são apresentadas as razões para sustentá-la. No trabalho descritivo, a conclusão será uma caracterização ou um fato novo; na pesquisa tipo associação, a descoberta de alguma associação; e na pesquisa tipo associação com interferência, algum novo efeito ou mecanismo de ação.

A conclusão do artigo usado como exemplo é: "No acidente de trânsito não ocorre associação significativa entre lesão axonal difusa (LAD) e hematoma extradural (HED), mas os HED cursam com LAD". Tal conclusão está expressa de forma clara e precisa e deixa transparecer qual era o objetivo do trabalho (avaliar a associação entre HED e LAD) e o tipo da pesquisa (pesquisa de associação entre duas variáveis). O passo seguinte é expor os resultados que levaram a tal conclusão.

\section{Resultados}

Nesta seção são apresentados os resultados da execução do método para cumprir os objetivos. Os dados resultantes respondem à pergunta originada do objetivo e são organizados em função dele. Portanto, devem ser incluídos apenas os resultados necessários para sustentar a conclusão. A apresentação simples, precisa e numa sequência lógica permite ao leitor identificar, de imediato, o significado dos resultados e vislumbrar a conclusão.

As partes anteriores do texto (Introdução, Material e Métodos) dizem por que e como foram obtidos os resultados; as posteriores (Discussão) explicam o que os resultados significam. Embora seja a seção mais importante do relato, é geralmente a menor. Os resultados são apresentados em tabelas, figuras (gráfico, foto, desenho, esquema) ou texto.,

A melhor forma de evidenciar e elucidar um resultado é por meio de figuras. A seguir vem a tabela e, por último, o texto, que é a forma menos atrativa de apresentação dos resultados. Portanto, os principais resultados, aqueles fundamentais para sustentar a conclusão, devem, quando possível, ser colocados sob a forma de figuras.
O gráfico é a figura que expressa dados por meio de traços e pontos, numerados com algarismos arábicos. Ele mostra de que forma alguma coisa varia em relação a outra. Ele é, portanto, indicado para apresentar a evolução de uma variável, a comparação de valores médios ou de porcentagens, ou a ligação entre duas variáveis. Existem três tipos de gráficos: de curvas ou linear, de histograma ou de barras e de setores (ou em pizza ou em torta).

Os gráficos em linha ou curva são constituídos de valores de um mesmo grupo ou de vários grupos e traçados em sistema de coordenadas retangulares ou cartesianas. São ideais para exprimir variações contínuas em função do tempo e estabelecer correlações ou mudanças gradativas nos valores de variáveis independentes.

O histograma, ou gráfico em colunas ou barras, é formado por retângulos ou barras verticais ou horizontais. É ideal para variáveis nominais, que surgem quando são definidas categorias (sexo, características físicas, desempenho etc.).

O gráfico em pizza é particularmente adaptado para comparações de medidas dentro de um mesmo todo por meio de porcentagens.

A tabela reúne grande número de informações, ordenada em linhas e colunas, permitindo exame rápido e comparativo. É usada para apresentação de resultados numéricos, especialmente na pesquisa descritiva, em que os valores são, em si, a informação importante.

Apesar de ser a forma menos atrativa de apresentação de resultados, o texto é necessariamente usado para expor dados puramente descritivos.

No artigo usado como exemplo, os resultados dos 120 casos de vítimas fatais de acidentes de trânsito são mostrados em duas tabelas: $7 \mathrm{HED}(7,7 \%$; todos associados a LAD e coma); $91 \mathrm{LAD}(75,8 \%$; 7 associadas e 113 não associadas ao HED); não ocorreu associação significativa entre $\operatorname{HED}$ e LAD $(p=0,19)$. Portanto, os resultados sustentam a conclusão: "No acidente de trânsito não ocorre associação significativa entre LAD e HED, mas os HED cursam com LAD". O passo seguinte da redação é expor as informações metodológicas necessárias para a obtenção dos resultados apresentados.

\section{Material e métodos}

É a seção em que se descreve como o experimento foi feito, isto é, seu planejamento, a coleta de dados e a análise dos resultados. Devem ser incluídas apenas as informações metodológicas que sustentam os resultados.

Inicialmente, descreve-se claramente a seleção feita dos sujeitos observados ou que participam da experiên- 
cia (pacientes, animais etc.). A seguir, é exposto o planejamento ou delineamento do estudo. Esse delineamento deve ser um desdobramento do objetivo do estudo e mostrar a lógica e a dinâmica do experimento.

$\mathrm{Na}$ pesquisa descritiva, descreve-se um pedaço do todo (amostra) e valida-se essa descrição para o todo (população). A estratégia básica nesse tipo de pesquisa é a amostragem (sua caracterização e inferência para o todo), que deve ser evidenciada no delineamento (como foi a amostragem? qual o tamanho da amostra?).

$\mathrm{Na}$ pesquisa de associação sem interferência entre variáveis, as variáveis devem ser pareadas num mesmo indivíduo ou numa mesma relação temporal. No delineamento, devem ser indicados as variáveis, o que as une (mesmo sistema ou tempo) e o tamanho da amostra.

Na pesquisa de associação com interferência entre variáveis, o delineamento consiste em obter a variação do agente interferente (causa) e registrar o comportamento da variável efeito. Devem ser indicados as condições de manipulação do suposto agente interferente, $o$ que será avaliado como efeito e o número de repetições de cada manipulação.

Após exposição do delineamento, fica fácil para o leitor a compreensão dos procedimentos específicos. Nessa parte, são mostrados os detalhes da metodologia utilizada, como coleta de dados, métodos de medida e especificações de técnica. Finalmente, é apresentado como os dados foram analisados (métodos estatísticos). Os experimentos são relatados no passado.

No artigo usado como exemplo, a seção Material e Métodos inicia com a seleção e descrição dos sujeitos: 120 vítimas fatais de acidente de trânsito. A seguir, é exposto o planejamento ou delineamento do estudo: avaliação do estado de consciência à admissão hospitalar; necropsia; procedimentos específicos para o estudo anatomopatológico do encéfalo.

Finalmente, são anunciados o método para avaliação do estado de consciência (escala de coma de Glasgow) e o método para comparação de proporções (estudo da associação entre variáveis qualitativas): teste exato de Fisher.

Com essa metodologia (estudo macroscópico e microscópico do encéfalo), é possível identificar os casos de HED e LAD e estudar a associação entre as duas lesões.

\section{Discussão}

Na Discussão, discute-se para mostrar os argumentos que validam a conclusão. Portanto, a conclusão deve ser anunciada no início da Discussão e, a seguir, são apresentadas as informações importantes (premissas) para validá-la logicamente. Validam-se os métodos e os resultados e conecta-os em busca de provas para sustentar a conclusão. ${ }^{10}$

A validação dos métodos é realizada mostrando que o delineamento da pesquisa está adequado (com os devidos controles). Essa adequação pode ser evidenciada pelo fato de outros pesquisadores terem usado o mesmo delineamento da pesquisa em questão. Caso se trate de um delineamento (protocolo) criado pelo autor, a validação pode ser feita mostrando que ocorre controle dos fatores interferentes.

A validação dos resultados pode ser feita mostrando que: a) os valores-padrão (basais, testemunhas, controles) estão dentro dos limites descritos na literatura; b) os valores possuem baixa variabilidade em relação a outros estudos; c) algum efeito esperado ocorreu.

A validação da metodologia e dos resultados garante maior confiabilidade à conclusão, mas esta também deve ser validada por meio da demonstração de que é coerente com o conhecimento científico aceito e encaixa-se em uma grande teoria. As teorias apresentam certas implicações e pode-se mostrar que a conclusão reforça determinada implicação. Assim, a conclusão passa a apoiar-se numa teoria geral.

A argumentação desenvolvida deve seguir uma sequência lógica para resultar na conclusão do trabalho, fazendo desta uma decorrência lógica e natural de tudo o que foi exposto anteriormente. Ela estabelece, inicialmente, a correlação entre os dados e, a seguir, relaciona-os com a questão ou hipótese investigada. Compara também os resultados com aqueles da literatura. Finalmente, estabelece a conclusão. Essa é a consequência lógica do objetivo da pesquisa e dos resultados encontrados e discutidos.

No artigo usado como exemplo, a Discussão inicia-se pelo anúncio da conclusão: "No acidente de trânsito não ocorre associação significativa entre LAD e HED, mas os HED cursam com LAD”. Não é exposta a validação dos métodos (estudo anatomopatológico e escala de coma de Glasgow) por eles serem de uso universal. Passam-se a apresentar os argumentos para validação dos resultados. Mostra-se que a alta incidência de LAD e a baixa incidência de HED no acidente de trânsito estão de acordo com o observado na literatura e que os valores possuem baixa variabilidade em relação a outros estudos. O fato de todos os casos de HED terem cursado com coma desde a internação, sem intervalo livre, é um efeito esperado (devido à associação com LAD) que corrobora a validação dos resultados.

Os dados são correlacionados e, a seguir, relacionados com a questão ou hipótese investigada: associação entre LAD e HED. A conclusão surge como uma consequência lógica do objetivo da pesquisa e dos resultados encontrados e discutidos. 
Finalmente, são emitidos argumentos que procuram validar a conclusão por meio da demonstração de que ela é coerente com o conhecimento científico aceito e encaixa-se em uma grande teoria. A ausência de associação significativa entre a LAD e o HED é explicada pelo fato de ambas as lesões terem uma causa comum (trauma), mas mecanismos diferentes: enquanto o HED é lesão de contato (pouco importante no acidente de trânsito), a LAD é inercial (o mecanismo fundamental no acidente de trânsito). A associação de todos os casos de HED com LAD é explicada pela relação direta entre aceleração e impacto no acidente de trânsito, decorrente da teoria da deformação do crânio e da rotação da cabeça (Holborn, 1943). O impacto sobre a cabeça absorve parcialmente a força da aceleração ou da desaceleração brusca da cabeça. É necessária grande força de impacto para provocar o HED e, quando ela ocorre, a força inercial (aceleração) associada será também de intensidade suficiente para determinar deformação do tecido cerebral e lesão dos axônios. Uma implicação de tal teoria é que os casos de HED no acidente de trânsito devem cursar preferencialmente com coma imediato (devido à associação com LAD), sem intervalo livre. Foi o que ocorreu em todos os casos do estudo, o que reforça a validade da conclusão.

\section{Introdução}

A Introdução tem por função apresentar o objetivo (problema) que inspirou o trabalho, com a contextualização e as justificativas desse objetivo. É apresentada sob a forma de argumento, no qual a contextualização e as justificativas do trabalho são as premissas e o objetivo é a consequência lógica dessas premissas.

Inicia-se com a contextualização, mostrando a importância da pesquisa e definindo termos necessários.

$\mathrm{Na}$ justificativa, apresentam-se as razões para o objetivo proposto. Ela é fundamental, e a estratégia para justificar o objetivo dependerá do tipo de pesquisa. Na pesquisa descritiva, procura-se validar a descrição. Pode-se descrever algo porque é necessário e ainda não foi descrito. Algo já descrito pode ser descrito sob nova forma. Algo já descrito e de forma adequada pode ser descrito em outro contexto, em uma condição diferencial.

Na pesquisa de associação entre duas variáveis sem interferência, é possível conhecer o comportamento de uma variável observando o comportamento da outra. $\mathrm{Na}$ justificativa, pode-se mostrar a importância e a dificuldade de conhecer o comportamento da variável $\mathrm{X}$, decorrendo daí a necessidade de encontrar algum indicador (variável Y) do comportamento dela que seja de fácil análise. Para complementar a fundamentação, é necessário mostrar, por meio de razões lógicas, por que se espera que $\mathrm{Y}$ seja a variável associada a $\mathrm{X}$.

No caso de estudo de associação entre duas variáveis com hipótese de interferência, justifica-se por razões lógicas por que se espera que alguma coisa (causa) promova algum efeito.

Finalmente, o objetivo é anunciado de forma clara e precisa como pergunta a ser respondida ou hipótese a ser confirmada ou não. Deve ser inserido como consequência lógica da contextualização e das justificativas. Ele é a parte mais importante da Introdução e o guia para delineamento da pesquisa e análise dos resultados em direção à conclusão.

$\mathrm{Na}$ redação do objetivo, usa-se a forma infinitiva dos verbos.

Pesquisa descritiva: o objetivo é descrever...

Pesquisa de associação: o objetivo é testar a hipótese de que...

No artigo usado como exemplo, a Introdução inicia-se com a contextualização definindo e mostrando a importância do HED e da LAD no acidente de trânsito.

A seguir, são apresentadas as razões para justificar o objetivo proposto: como o HED é lesão de impacto e a LAD é de natureza inercial, e como no acidente de trânsito esses dois mecanismos podem coexistir, é de se esperar certa associação de ambas as lesões. Os autores ressaltam, ainda, que, apesar da hipótese de a LAD ser a responsável pela inconsciência imediata nos pacientes com HED sem intervalo livre, não existe nenhum relato anatomopatológico de associação dessas lesões.

Finalmente, o objetivo é anunciado, de forma clara e precisa, como consequência lógica da contextualização e das justificativas: estudar a associação de HED e LAD em vítimas de acidente de trânsito.

\section{Título}

O título é a versão mais simplificada e condensada do artigo. Como no artigo propriamente dito e no Resumo, ele deve refletir o que foi realizado no estudo (o conteúdo do trabalho), de modo que, mesmo quando publicado separadamente, permita identificar a natureza e o conteúdo do trabalho. ${ }^{2}$

O primeiro contato entre o leitor e o trabalho é, geralmente, por meio do título, nos bancos de dados online. Portanto, deve ser bem construído para chamar a atenção do leitor. Deve ser conciso, claro e expressar o conteúdo do trabalho. Como o título deve expressar a essência do trabalho, a conclusão e o objetivo (as partes mais essenciais do trabalho) são os guias na construção dele.

O título não necessita ser formulado como oração gramatical completa, com sujeito, predicado e comple- 
mento. Devem-se evitar expressões dispensáveis, como: a propósito de; considerações sobre; contribuição para o conhecimento de; estudo de; estudo sobre; influência dos; interesse de; investigações sobre; observações sobre. Tais expressões nada acrescentam, além de alongar, inutilmente, o título. É evidente que, por exemplo, o presente texto sobre redação do artigo científico constitui estudo sobre o tema, fará considerações sobre ele e pretende contribuir para ele, sendo desnecessário e redundante reforçar isso no título.

Deve existir estreita correlação entre o objetivo, a conclusão e o título. O primeiro (pergunta) determina o segundo (resposta) e ambos determinam a construção do título.

No artigo usado como exemplo, o título é: "Lesão axonal difusa e hematoma extradural em vítimas fatais de acidente de trânsito". Ele reflete o que foi realizado no estudo (o conteúdo do trabalho) e o tipo da pesquisa (associação entre duas variáveis): estudo da associação entre LAD e HED. Note-se que "estudo da associação entre" foi omitido, pois é desnecessário (está implícito) e nada acrescenta em informação.

Existe estreita correlação entre o objetivo (problema), a conclusão (resposta ao problema) e o título (que indica a natureza e conteúdo do trabalho):

- objetivo: estudar a associação de HED e LAD em vítimas fatais de acidente de trânsito;

- conclusão: no acidente de trânsito não ocorre associação significativa entre LAD e HED, mas os HED cursam com LAD;

- título: lesão axonal difusa e hematoma extradural em vítimas fatais de acidente de trânsito.

\section{Resumo}

Resumo é a apresentação sintética dos pontos relevantes do texto. ${ }^{1}$ É sua versão reduzida mais minuciosa que o título e menos que o todo. Deve permitir rápida informação e avaliação do texto completo e refletir, fielmente, os dados fundamentais da investigação. Para tal, deve formar um todo, podendo, assim, ser publicado independentemente nos sistemas eletrônicos de indexação.

O Resumo deve apresentar o seguinte conteúdo: ${ }^{4}$

- Introdução: o objetivo é apresentado no início e deve expressar qual questão específica a que se deseja responder. Muitas vezes tal objetivo é omitido por já estar expresso no Título.

- Material e Métodos: mencionam-se o material ou casuística e os métodos usados para se obterem os resultados.

- Resultados: são enumerados aqueles principais, indicando os valores mais representativos, com significação estatística.
- Conclusão ou interpretação: descrevem-se as consequências dos resultados e o modo como elas se relacionam com os objetivos propostos, respondendo, assim, à questão expressa no início.

O Resumo é tradicionalmente redigido em parágrafo único composto por frases cuja sequência corresponde aproximadamente às partes do texto: Introdução, Material e Métodos, Resultados e Conclusão. Há, entretanto, tendência a adotar-se o resumo estruturado, dividido em quatro parágrafos com cada uma dessas informações.

$\mathrm{O}$ artigo usado como exemplo tem o seguinte resumo:

Lesão axonal difusa e hematoma extradural em vítimas fatais de acidente de trânsito.

Descrevem-se sete casos de vítimas de acidente de trânsito com hematoma extradural (HED) e lesão axonal difusa (LAD). Esses casos fazem parte de um total de 120 vítimas fatais de acidente de trânsito que foram submetidas a estudo anatomopatológico. A associação entre as duas lesões ocorreu em apenas 5,8\% dos pacientes, mas todos os casos de HED apresentavam também LAD. Esta última lesão explica o coma imediato (ausência de intervalo livre) e o mal prognóstico em todos os pacientes. Observou-se que os HED são relativamente pouco frequentes no acidente de trânsito, mas, nesses casos, são mais graves pela frequente associação com LAD e coma imediato.

No texto acima, são apresentados a casuística e os métodos usados para se obterem os resultados. São enumerados apenas os resultados principais. Conclui-se com a interpretação dos resultados. Nota-se que não é colocado o objetivo, pois ele está implícito no título.

\section{Referências bibliográficas}

Referência Bibliográfica é a listagem das referências citadas no texto, de tal forma que permita a identificação dos documentos impressos. Dois sistemas são mais usados: o autor-data ou sobrenome-ano (Sistema de Harvard) e o numérico ou em sequência ou de ordem de citação (Sistema de Vancouver). ${ }^{4}$ Existe também o sistema numérico-alfabético, uma associação dos dois anteriores. Cada publicação periódica traz, entre as instruções aos colaboradores, as regras a se seguir para a citação das referências bibliográficas. $\mathrm{O}$ sistema autor-data é usado principalmente em livros e teses e o numérico, em artigos.

A referência bibliográfica é feita em dois passos: inserção da citação no texto e constituição da lista das referências bibliográficas.

A inserção da citação no texto é feita sob a forma de reprodução de ideias e informações do documento, 
sem, entretanto, transcrever as palavras do autor. Todos os trabalhos citados devem constar das Referências Bibliográficas, e todos os trabalhos aí listados devem ter sido citados no texto. A concisão exigida no texto científico é também requerida nas citações. Deve-se incluir somente as necessárias e essenciais para validar a metodologia, os resultados e a conclusão.

A seção Referências Bibliográficas, última parte do texto, compreende a ordenação sistemática dos trabalhos referidos. Essa citação deve seguir as normas recomendadas pelo periódico a que se destina o artigo. Dependendo do sistema adotado, as referências bibliográficas são numeradas por ordem consecutiva de sua citação no texto (sistema numérico) ou por ordem alfabética (sistemas autor-data).

Durante a redação do trabalho, recomenda-se usar o sistema autor-data. Esse sistema é o mais indicado para essa fase, por ser independente do término do levantamento bibliográfico e pela facilidade de serem acrescentadas e retiradas citações sem alterar a numeração final da lista de referências. Se for necessário ordenar as referências no sistema numérico, isso é realizado somente após a inserção de todas as referências no texto e a verificação de que todos os documentos citados estão na lista de referências bibliográficas e de que esta não contém documentos não citados. A mudança do sistema autor-data para o numérico só deve ser feita após o trabalho estar concluído. ${ }^{3}$

\section{Linguagem científica}

Durante a redação do texto, devemos nos ater primeiro ao conteúdo, ou seja, às partes metodológicas e aos elementos da argumentação para validar a conclusão. A seguir, procura-se adequar a forma, realizando a melhor construção para dizer o conteúdo.

As qualidades essenciais da forma do texto científico são clareza e concisão. ${ }^{2,10}$ A clareza consiste na expressão límpida do pensamento, na transparência ou nitidez que torna o texto facilmente compreensível. Quanto mais simples a linguagem, maior será a clareza para deixar transparecer o conteúdo do trabalho. Para atingir a linguagem clara: 1) use frases curtas e na ordem direta (sujeito, verbo e complemento); 2) escolha palavras acessíveis ao maior número possível de leitores; 3 ) opte pela palavra mais simples que defina a coisa ou situação referida; 4) evite os termos técnicos desnecessários e, quando absolutamente indispensáveis, não deixe de explicá-los; 5) use o tempo verbal apropriado.

O tempo verbal varia com a lógica de cada parte. A descrição dos sujeitos, da metodologia da pesquisa
(Material e Métodos) e dos resultados (Resultados) é feita no passado. As citações de ideias e conclusões de outros autores e a conclusão do trabalho são colocadas no tempo presente. Na redação do objetivo, usa-se o infinitivo. No passado, preferia-se a forma impessoal na redação, mas atualmente a tendência é o uso da primeira pessoa (eu ou nós). Isso é mais apropriado, pois a interpretação que o autor faz dos dados é pessoal e não será necessariamente a mesma dos leitores, como parece sugerir a linguagem impessoal.

Concisão é o emprego do menor número possível de palavras para exprimir o pensamento. A concisão confere ao estilo particular vigor. As palavras dispensáveis poluem o texto. Para alcançar concisão, devem-se excluir pormenores insignificantes e características irrelevantes, eliminar palavras e adjetivos inúteis e suprimir repetições das mesmas ideias. Segundo Picasso, “a arte é a eliminação do que é desnecessário". Isso é válido também para a arte da redação do texto científico.

Para conseguir clareza e concisão, é necessário rever o texto várias vezes para corrigi-lo e cortar o supérfluo. O resultado ideal é a formulação mais simples, com economia de palavras.

\section{Referências}

1. Comroe JH. Tell it like it was. Retrospective: Insights into medical discovery. Menlo Park, CA: Von Gehr Press; 1977.

2. Day RA. How to write and publish a scientific paper. 5th ed. Phoenix: Oryx Press; 1998.

3. Gusmão S, Silveira RL. Redação do trabalho científico na área biomédica. Rio de Janeiro: Revinter; 2000.

4. International Committee of Medical Journal Editors: Uniform requirements for manuscripts submitted to biomedical journals. N Engl J Med. 1997;336:309-15.

5. Magnusson WE. How to write backwards. Bull Ecol Soc Am. 1996;77:88.

6. Murlow CD. The medical review article: state of the science. Ann Intern Med. 1987;106:485-8.

7. Popper KR. A lógica da pesquisa científica. São Paulo: Cultrix; 1975.

8. Ramón y Cajal S. Reglas y consejos sobre investigación científica. Madrid: Aguilar; 1961.

9. Volpato GL. Método lógico para redação científica. Botucatu: Best Writing; 2011.

10. White EB, Strunk W. The elements of style. New York: MacMillian; 1972.

Endereço para correspondência

Sebastião Gusmão

Rua Otoni, 909 - Sala 410

30150-270 - Belo Horizonte, MG

Phone: (31) 3273-0511

E-mail: sebastiaogusmao@gmail.com 